(c) American Dairy Science Association, 2003.

\title{
Technical Note: Detection and Adjustment of Abnormal Test-Day Yields
}

\author{
G. R. Wiggans, P. M. VanRaden, and J. C. Philpot \\ Animal Improvement Programs Laboratory, Agricultural Research Service \\ USDA, Beltsville, MD 20705-2350
}

\section{ABSTRACT}

A method to detect and to adjust or exclude abnormally low or high milk, fat, and protein yields on testday (TD) was developed. Predicted TD yield is calculated based on preceding and subsequent (if available) TD yields. Observed TD yields that are $<60 \%$ or $>150 \%$ of predicted TD yield are defined as abnormal. Most abnormal yields are adjusted to this floor or ceiling, but some are excluded. Yields of $<4.5 \mathrm{~kg}$ that are identified as from a cow that was sick or that are less than half the mean of adjacent tests are excluded as are yields of $>59 \mathrm{~kg}$ above predicted yield. Lactation yields are calculated from the restricted TD yields. When this procedure was applied to 2002 data, $1.8 \%$ of milk, $2.4 \%$ of fat, and $1.6 \%$ of protein yields on TD were below the acceptance range and $0.1 \%$ of milk and protein and $0.8 \%$ of fat were above. Predicted TD yield was calculated as preceding TD yield plus preceding test interval multiplied by daily yield change (slope) based on days in milk (DIM), DIM ${ }^{2}$, previous normal TD yield, and interaction between DIM and previous TD yield. To accommodate changes in slope at peak yield, separate coefficients were estimated for $<50$ and $\geq 50$ DIM. Herd mean was used when only one TD was recorded for a cow (or when two were recorded and the second was designated as abnormal based on the first) and to determine an acceptable range for component percentages. Predicted TD yield for first TD was based on subsequent rather than previous normal TD. To test the adjustments, lactation records with one abnormal TD yield or more were matched with subsequent lactation records. Correlation between consecutive lactations increased from 0.692 to 0.693 for milk (561,063 lactation pairs), from 0.653 to 0.660 for fat (951,387 lactation pairs), and from 0.686 to 0.694 for protein $(488,653$ lactation pairs). Outlier adjustment improved the correlation between consecutive lactation yields and is applied routinely to TD records of cows for calvings since 1997.

Received December 20, 2002.

Accepted March 19, 2003.

Corresponding author: G. R. Wiggans; e-mail: wiggans@aipl. arsusda.gov.
(Key words: test day, abnormal yield, outlier detection, yield adjustment)

\section{Abbreviation key: TD = test day . \\ INTRODUCTION}

Because of sickness, injury, or recording error, a reported 24-h test-day (TD) yield may not be representative of either the cow's actual yield or her genetic ability. Recording guidelines of the International Committee for Animal Recording (1995) state: "True daily test values collected from animals labeled by the farmer as sick, injured, under treatment, or on heat must be used in the computation of the lactation record unless the milk yield is less than $50 \%$ of the previous milk yield or less than $60 \%$ of the predicted yield. In such a case, the whole set of daily test values may be considered as missing." Similarly, uniform operating procedures of the National DHI Program (National Dairy Herd Improvement Association, 2002) in the United States allow a TD yield to be adjusted if it has been coded as abnormal and falls below [72.6\% - 0.4 (days in previous test interval)] of previous TD yield. That procedure is applied as the lactation data are accumulated but does not use information from the subsequent TD to determine if reduction in yield continued.

Lactation records used in US national genetic evaluations for calvings since January 1997 are calculated using best prediction (VanRaden, 1997). When the best prediction method was implemented, all TD yields for which the cow was coded as sick were excluded from calculation of lactation yields because no procedure had been developed to determine if those TD yields qualified for exclusion. Some cows were coded as sick with TD yields of $>45 \mathrm{~kg}$, whereas other cows had large TD yield decreases but were not coded as sick. Because reporting of the sick code is not uniform across herds or dairy records processing centers, additional ways of detecting abnormal yields are desirable. Although all TD milk yields of $>123 \mathrm{~kg}$ are rejected, abnormal TD yields should include yields that are unusually high in comparison with the cow's other yields as well as some low yields with or without a sick code.

The purposes of this research were to develop methods to detect abnormal TD yields, to adjust or to exclude 
those yields when estimating lactation yield, and to determine whether accuracy of lactation yield estimates was improved by use of such methods.

\section{METHOD FOR OUTLIER DETECTION AND ADJUSTMENT}

\section{Data}

Over 93 million TD yields of milk and associated fat and protein percentages from records in the US national database were examined for all parities of cows of all breeds that calved from 1997 through 2001. Data only from calvings during 2000 and lactations with three tests or more with milk, fat, and protein information (16.7 million TD records) were used to estimate lactation curve parameters. Frequency of abnormal yields by breed, parity, and lactation stage were from TD during 2002.

\section{Determination of Thresholds}

Thresholds that would identify about $2 \%$ of TD data as abnormal were desired. Because a cow is less likely to have a large increase in yield than to have a large decrease, thresholds were designed primarily to identify low yields as abnormal. Preliminary investigation showed that a floor of $60 \%$ of predicted TD yield as specified by the International Committee for Animal Recording (1995) is a reasonable lower limit. An upper limit of $150 \%$ was selected to cap the most extreme yields. Those thresholds were also used for fat and protein yields. Any TD yield designated as abnormal was not used to assess normality of yield on other TD. When TD milk yield was $<4.5 \mathrm{~kg}$, TD data were not used to detect abnormal TD yields or to calculate lactation yields if the cow was coded as being sick or if TD yield was less than half the mean of the two adjacent TD yields. If milk yield was $>59 \mathrm{~kg}$ above predicted yield, TD yield was assumed to be a recording error and excluded.

\section{Estimation of Lactation Curve Parameters}

Parameters for estimation of the slope of the lactation curve were estimated separately for milk, fat, and protein from adjacent TD yields:

$$
\begin{gathered}
\left(\mathrm{y}_{\mathrm{i}}-\mathrm{y}_{\mathrm{i}-1}\right) /\left(\mathrm{DIM}_{\mathrm{i}}-\mathrm{DIM}_{\mathrm{i}-1}\right)=\mathrm{b}_{0}+\mathrm{b}_{1} \mathrm{DIM}_{\mathrm{i}-1}+\mathrm{b}_{2} \mathrm{DIM}_{\mathrm{i}-1}^{2} \\
+\mathrm{b}_{3} \mathrm{y}_{\mathrm{i}-1}+\mathrm{b}_{4}\left(\mathrm{DIM}_{\mathrm{i}-1}\right) \mathrm{y}_{\mathrm{i}-1}+\mathrm{e},
\end{gathered}
$$

where $\mathrm{y}_{\mathrm{i}}=$ yield on TD i; $\mathrm{y}_{\mathrm{i}-1}=$ yield on preceding TD; $\mathrm{b}_{0, \ldots, 4}=$ regression coefficients that vary by trait (milk, fat, or protein), lactation stage ( $<50$ or $\geq 50 \mathrm{DIM})$ at $\mathrm{TD}_{\mathrm{i}}$, and parity ( 1 or $\geq 2)$; and e = random residual. Separate coefficients were estimated for the two lactation stages to accommodate initial rise to peak yield and subsequent decline. Inclusion of yield on preceding TD enabled the estimated slope to change with yield level. For estimation of curve parameters, data limits were 18.1 to $57.6 \mathrm{~kg}$ for TD milk yield, 0.5 to $2.2 \mathrm{~kg}$ for TD fat yield, 0.5 to $1.6 \mathrm{~kg}$ for TD protein yield, 25 to $39 \mathrm{~d}$ for TD interval, and $<330 \mathrm{~d}$ for TD DIM. A separate set of regression coefficients was estimated based on subsequent rather than preceding TD yield to allow prediction of first TD yield. A computer program that includes the estimated coefficients is available online at ftp://aipl.arsusda.gov/pub/outgoing/limittdy.c.

\section{Detection of Abnormal TD Yield}

Reported TD milk, fat, and protein yields were compared separately with a predicted TD yield that was estimated from yields on adjacent TD. For the first TD of a lactation, predicted yield was estimated from yield on the subsequent TD with normal yield:

$$
\hat{\mathrm{y}}_{1}=\mathrm{y}_{2}+\hat{\mathrm{b}}\left(\mathrm{DIM}_{2}-\mathrm{DIM}_{1}\right)
$$

where $\hat{\mathrm{y}}_{1}=$ predicted yield on first TD, $\mathrm{y}_{2}=$ observed yield on subsequent TD, $\hat{b}=b_{0}+b_{1} D_{I M}+b_{2} D_{2} I_{2}^{2}+$ $\mathrm{b}_{3} \mathrm{y}_{2}+\mathrm{b}_{4}\left(\mathrm{DIM}_{2}\right) \mathrm{y}_{2}$ using $\mathrm{b}_{0, \ldots, 4}$ estimated above, and $\mathrm{DIM}_{2}-\mathrm{DIM}_{1}=$ interval between first and subsequent TD. If yield on the subsequent TD was not available or was considered to be abnormal, yield on first TD was compared with annual herd mean that had been adjusted to corresponding DIM.

For TD other than first, predicted yield was estimated from yield on preceding TD with normal yield:

$$
\hat{y}_{i}=y_{i-1}+\hat{b}\left(D_{I M}-D_{i-1}\right),
$$

where $\hat{y}_{i}=$ predicted yield on TD other than first, $y_{i-1}$ $=$ observed yield on preceding TD, and $\hat{b}$ is estimated as for first TD except based on preceding rather than subsequent TD. If $y_{i}$ was considered to be abnormal, a new predicted yield was calculated using a slope based on a preceding and a subsequent TD with normal yield. This complexity in confirming abnormality avoids incorrect designations when a TD is consistent with most other TD for a lactation. For example, a TD with a large yield decrease would not be designated as having abnormally low yield if yield on the following TD also was low. An abnormal TD yield for milk does not force TD component yields to be designated as abnormal; when milk yields are depressed, component percentages often increase in partial compensation. 


\section{Adjustment of Abnormal TD Yield}

Excluding abnormal TD yields when calculating lactation yields is equivalent to weighting reported data by 0 . Imposing a floor or ceiling for abnormal TD yields is equivalent to reducing their weight in calculation of lactation yields and allows TD yields that are only slightly beyond the threshold to contribute information. Although adjusted yields could be differentially weighted depending on their deviation from predicted yield, such an adjustment would add complexity to the best prediction procedure. The TD yields of $<60 \%$ of predicted TD yield were increased to that floor, and TD yields of $>150 \%$ of predicted TD yield were reduced to that ceiling except for extremely high yields, which were excluded.

Although abnormality of TD fat and protein yields was determined with the same system as for TD milk yield, limits also were imposed on TD component percentages in addition to TD yields. Without such limits, application of a floor or ceiling to TD component yields could create unlikely component percentages, particularly if TD milk yield had been adjusted. Fat percentage was limited to 2 to $7 \%$ and also constrained to herd mean $-1 \%$ to herd mean $+2 \%$. Protein percentage was limited to 2 to $5 \%$ and also to herd mean $-1 \%$ to herd mean $+1.5 \%$.

\section{Lactation Yield Accuracy}

Lactation yields were computed from observed and adjusted TD yields for each lactation that had one adjusted TD yield or more for milk, fat, or protein. Correlations were calculated between lactations with an abnormal TD yield and the subsequent lactation both with and without adjustment of abnormal TD yield.

\section{RESULTS}

Overall, $1.8 \%$ of milk, $2.4 \%$ of fat, and $1.6 \%$ of protein yields for TD during 2002 were detected as abnormally low. Distribution of abnormally low milk yields is in Figure 1 by DIM and parity. The highest percentages of TD yields that were abnormally low were during early and late lactation, when yields are most variable. Distribution of abnormally low protein yields (not shown) was similar to that for milk. For fat (not shown), slightly above $2 \%$ of TD yields were abnormally low for parities 2 through 5 until 225 DIM, when the percentage of TD with abnormal yield began to increase. For first parity, distribution of abnormally low fat yields was similar to that for milk during early lactation but with only a small increase in later lactation.

Abnormally high yields were found for $0.1 \%$ of milk and protein and $0.8 \%$ of fat TD yields during 2002 .

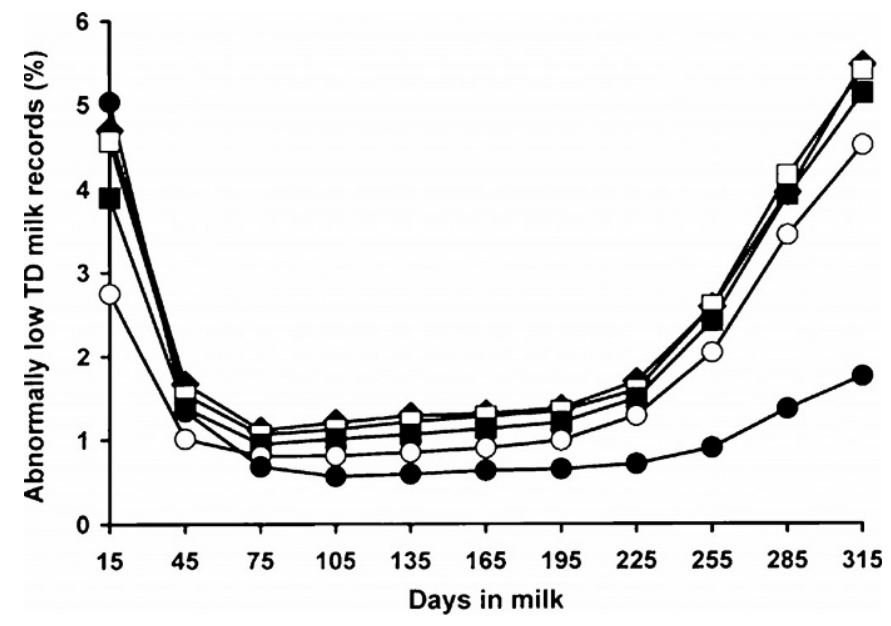

Figure 1. Percentage of test-day (TD) records with abnormally low milk yields by days in milk and parity $(-$ first, $\bigcirc=$ second, $\boldsymbol{\square}$ = third, $\square=$ fourth, and $\diamond=$ fifth).

Distribution of abnormally high TD milk yields is in Figure 2 by DIM and parity. Higher percentages of abnormally high TD yields tended to be during early and late lactation, except for first parity, for which the percentage remained nearly constant across DIM. Distribution of abnormally high fat yields (not shown) was similar to that for milk yield except for no increase in later lactation. Abnormally high TD protein yields also had a similar distribution (not shown) to abnormally high milk yields except for lower percentages during early lactation. The higher overall percentage of TD fat yields that were below $60 \%$ or above $150 \%$ of predicted TD yield reflects that trait's greater variability. However, differences in number of outliers were judged not

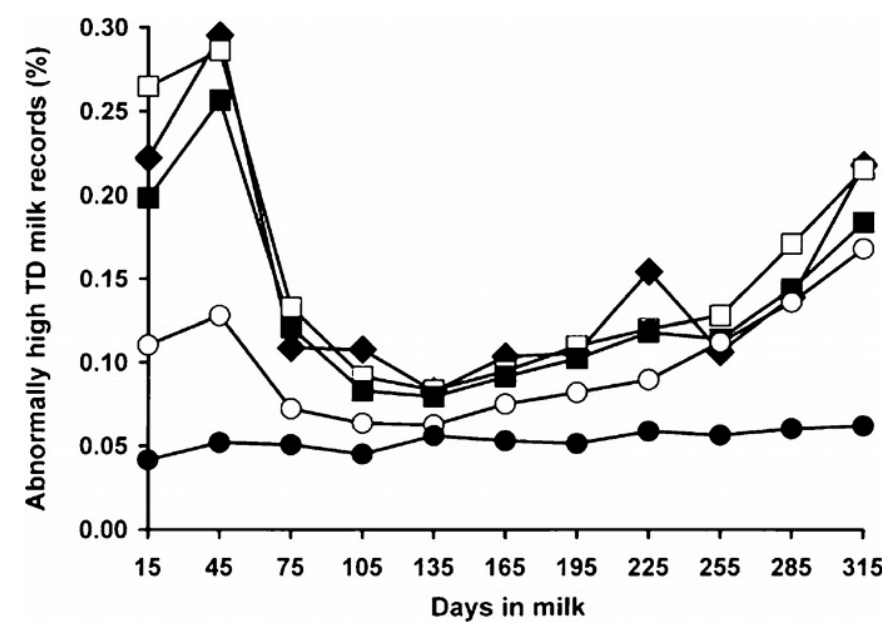

Figure 2. Percentage of test-day records with abnormally high milk yields by days in milk and parity $(-$ first, $\bigcirc=$ second, $\mathbf{\square}=$ third, $\square=$ fourth, and $\bullet=$ fifth). 
Table 1.Correlations between consecutive lactation yields calculated with and without adjustment of abnormal test-day yields in the earlier lactation.

\begin{tabular}{llll}
\hline \multirow{2}{*}{$\begin{array}{l}\text { Yield } \\
\text { trait }\end{array}$} & $\begin{array}{l}\text { Lactation } \\
\text { pairs } \\
\text { (no.) }\end{array}$ & \multicolumn{2}{c}{ Correlation } \\
\cline { 3 - 4 } & 561,063 & No adjustment & Adjustment \\
\hline Milk & 951,387 & 0.652 & 0.693 \\
Fat & 983,653 & 0.686 & 0.660 \\
Protein & 488,65 & 0.694 \\
\hline
\end{tabular}

to be large enough to require different thresholds for each yield trait. Results were similar when determined separately from records of Holstein and Jersey cows.

Between 488,000 and 952,000 cows had consecutive lactations in which the earlier lactation had at least one abnormal TD yield for milk, fat, or protein. For all traits, correlation between consecutive lactation yields (Table 1) was greater when yield for the earlier lactation was calculated using adjusted yield for abnormal TD yields. The improvement was greatest for component yields.

Although reported TD yields that have been determined to be abnormal may be valid, they may not be representative of the monthly yield that they are intended to predict. By adjusting the reported yield to a floor or ceiling, the abnormal observation is retained, but its influence on calculation of lactation yield is reduced. By restricting TD yields based on their predicted values, the impact of abnormal yields that are the result of reporting errors also is minimized (i.e., the calculated lactation yield is more similar to what would have been calculated by best prediction without the erroneous data).

The outlier adjustment method based on a floor and ceiling prevents two similar TD yields that fall on opposite sides of the threshold from having substantially different effects on calculation of lactation yield. The limits also reduce impact of recording errors for both low and high yields. The most extreme TD yields are excluded: high yields because they are likely to be coding errors and low $(<4.5 \mathrm{~kg})$ yields because they make assessment of other TD less accurate.

\section{Implementation}

This procedure of detection and adjustment of abnormal TD yields was implemented for August 2002 USDA-DHIA genetic evaluations for yield traits and was used to recalculate lactation yields of all cows that calved during 1997 or later. As data are received at the Animal Improvement Programs Laboratory (Beltsville, $\mathrm{MD})$, the outlier adjustment procedure is applied, and abnormal TD yields are returned to the dairy records processing centers for possible relay to herd managers or technicians to assist in detection of recording errors. Recording errors may result from meter malfunctions or improper sampling as well as from data entry errors or incorrect cow identification. Adjusted TD yields are available to industry cooperators at the Animal Improvement Programs Laboratory web site (http:// aipl.arsusda.gov).

\section{ACKNOWLEDGMENTS}

Manuscript review by A. H. Sanders and S. M. Hubbard of the Animal Improvement Programs Laboratory (Beltsville, MD) is appreciated.

\section{REFERENCES}

International Committee for Animal Recording. 1995. Recording Guidelines: Appendices to the International Agreement of Recording Practices. ICAR, Rome, Italy. Online. Available: http:// www.icar.org/pdf\%20files/rules\%20and\%20regulations/ guidelines.pdf. Accessed Sept. 11, 2002.

National Dairy Herd Improvement Association. 2002. National Dairy Herd Improvement Program uniform operating procedures (effective June 2002). Online. Available: http://www.dhia.org/uop.pdf. Accessed June 23, 2003.

VanRaden, P. M. 1997. Lactation yields and accuracies computed from test day yields and (co)variances by best prediction. J. Dairy Sci. 80:3015-3022. 